\title{
Experimental Study on Reinforcement of Biological Enzyme for Road Soil
}

\author{
Zhang Yemin ${ }^{1}$, Hu Xuanqing ${ }^{1, ~ a ~, L i ~ Z h e n ~}{ }^{2, b}$ \\ ${ }^{1}$ Shenyang University, Shenyang \\ ²Beijing Jian Da Road Bridge Consulting Limited company, Beijing \\ a1501112513@qq.com, b596361791@qq.com
}

\section{Keywords: Biological enzyme; Soil consolidation; Comparison test; Road performance}

Abstract. Biological enzyme is a new type of soil reinforcement material, it is based on biological enzymes curing agent to achieve. As a biological enzyme reinforcement material, its greatest advantage is no pollution to the environment, but also to ensure good mechanical and road performance. In order to study the mechanical properties of this experiment, the liquid limit, plastic limit and direct shear test were made ; and then through the compression modulus test and splitting test as a comparison test to test its road performance. Finally, through the comparison of experimental data: the bio-enzyme-cured soil has better mechanical properties than natural soils and has good road performance compared to conventional road soils.

\section{Introduction}

The road has always been an indispensable link to every city, at the same time the quality of the road is also determined by the various factors. This article describes the biological enzyme soil reinforcement technology, which is a new soil reinforcement technology, at present in some developed countries have been widely used, and the reinforcement effect is good. Therefore, the end of the last century China began to introduce soil curing agent, and achieved the corresponding achievements. There are some limitations such as it can not meet the requirements of different regional road design specifications ${ }^{[1,3]}$. For ordinary curing agent, there are often some bad phenomenons such as: low strength, poor soil stability, poor frost resistance ${ }^{[6]}$.

The enzyme soil curing technology introduced in this paper is a new type of technology based on the biological enzyme. And this biological enzyme curing agent is still a green pollution-free, easy to use the use of new materials, can be very suitable for China's complex and varied terrain characteristics.

\section{Technical properties of raw materials}

The test soil is cohesive soil in Shenyang City, Liaoning Province. Its physical characteristics: soil density is $\rho=2.19 \mathrm{~g} / \mathrm{cm}^{3}$, the water content is $23.08 \%$. In order to avoid the impact of the subsequent test data, the collected soil sample must be stored in accordance with its original physical environment. Biological Enzyme Curing Agent is a liquid reagent provided by a company in Yantai, Shandong Province. Biological enzyme is a kind of biocatalytic enzyme type soil curing agent, its main component is compound lactic acid bacteria, the color is dark red, slightly irritating smell. The choice of biological enzyme curing agent its density is $\rho=1.01 \mathrm{~g} / \mathrm{cm}^{3}$, the density slightly higher than water.

\section{Comparison test of engineering properties of solidified soil}

\section{Liquid limit, plastic limit test}

The liquid plastic limit of soil is divided into liquid limit and plastic limit, and liquid limit is the boundary water content of cohesive soil when it changes from flowing state to plastic state. Plastic limit refers to the bounded water content of the cohesive soil from the plastic state to the semi-solid state ${ }^{[4]}$. For liquid limit test, we use cone liquid limit tester to test and for the determination of plastic limit, we 
use the more conventional rolling method. The preparatory work should be carried out in strict accordance with the test requirements and do more than a few groups of experiments to compare. Selection of qualified sample group data and calculation, we can draw the following conclusions:

(1) The liquid limit of the original soil $\omega_{L 1}=29.63 \%$, the liquid limit of the cured soil $\omega_{L 2}=28.33 \%$, by comparison $\omega_{L 1}>\omega_{L 2}$. It can be seen that the soils with soil enzyme is less soiled, the strength is higher, the soil stability is better, and the curing effect is achieved.

(2) The liquid index of undisturbed soil is $I_{L 1}=46.49 \%$ and the liquid index of the cured soil is $I_{L 2}=43.72 \%$. By comparison we can see $I_{L 1}>I_{L 2}$. That is, the soil enzyme with enzyme has less liquid index, and the soil is stronger and has reinforcing effect.

\section{Direct shear test}

The test method was divided into the test group and the solidified soil test group by the fast cutting method, four vertical pressure were $0.1 \mathrm{MPa}, 0.2 \mathrm{MPa}, 0.3 \mathrm{MPa}, 0.4 \mathrm{MPa}$, The test data were obtained by three tests. According to Coulomb's law ,Including two indicators: determination of cohesion $\mathrm{C}$ and friction angle $\varphi$.

Table 3.1 Shear strength of undisturbed soil

\begin{tabular}{|c|c|c|c|c|c|c|c|c|c|c|c|c|}
\hline & \multicolumn{3}{|c|}{$0.1 \mathrm{MPa}$} & \multicolumn{3}{c|}{$0.2 \mathrm{MPa}$} & \multicolumn{3}{c|}{$0.3 \mathrm{MPa}$} & \multicolumn{3}{c|}{$0.4 \mathrm{MPa}$} \\
\hline $\mathrm{C}$ & 1.68 & 1.68 & 1.68 & 1.68 & 1.68 & 1.68 & 1.68 & 1.68 & 1.68 & 1.68 & 1.68 & 1.68 \\
\hline $\mathrm{R}$ & 12.40 & 12.40 & 12.40 & 23.80 & 23.70 & 23.80 & 41.40 & 40.00 & 40.00 & 55.20 & 53.00 & 53.00 \\
\hline$\tau_{f}$ & 20.83 & 20.83 & 20.83 & 39.98 & 39.82 & 39.98 & 69.55 & 67.20 & 67.20 & 92.74 & 89.04 & 89.04 \\
\hline
\end{tabular}

Table 3.2 Cured soil shear strength

\begin{tabular}{|c|c|c|c|c|c|c|c|c|c|c|c|c|}
\hline & \multicolumn{3}{|c|}{$0.1 \mathrm{MPa}$} & \multicolumn{3}{c|}{$0.2 \mathrm{MPa}$} & \multicolumn{3}{c|}{$0.3 \mathrm{MPa}$} & \multicolumn{3}{c|}{$0.4 \mathrm{MPa}$} \\
\hline $\mathrm{C}$ & 1.68 & 1.68 & 1.68 & 1.68 & 1.68 & 1.68 & 1.68 & 1.68 & 1.68 & 1.68 & 1.68 & 1.68 \\
\hline $\mathrm{R}$ & 28.10 & 29.00 & 28.10 & 65.40 & 65.40 & 62.50 & 76.00 & 76.00 & 92.20 & 115.50 & 115.50 & 121.40 \\
\hline$\tau_{f}$ & 47.21 & 48.72 & 47.21 & 109.87 & 109.87 & 105.0 & 127.68 & 127.7 & 154.9 & 194.04 & 194.04 & 203.95 \\
\hline
\end{tabular}

From the micrometer reading, it can be clearly seen that the stability value of the solidified soil test group is higher than that of the undisturbed soil test group. From the following regression equation we can obtain its cohesive force and internal friction angle.
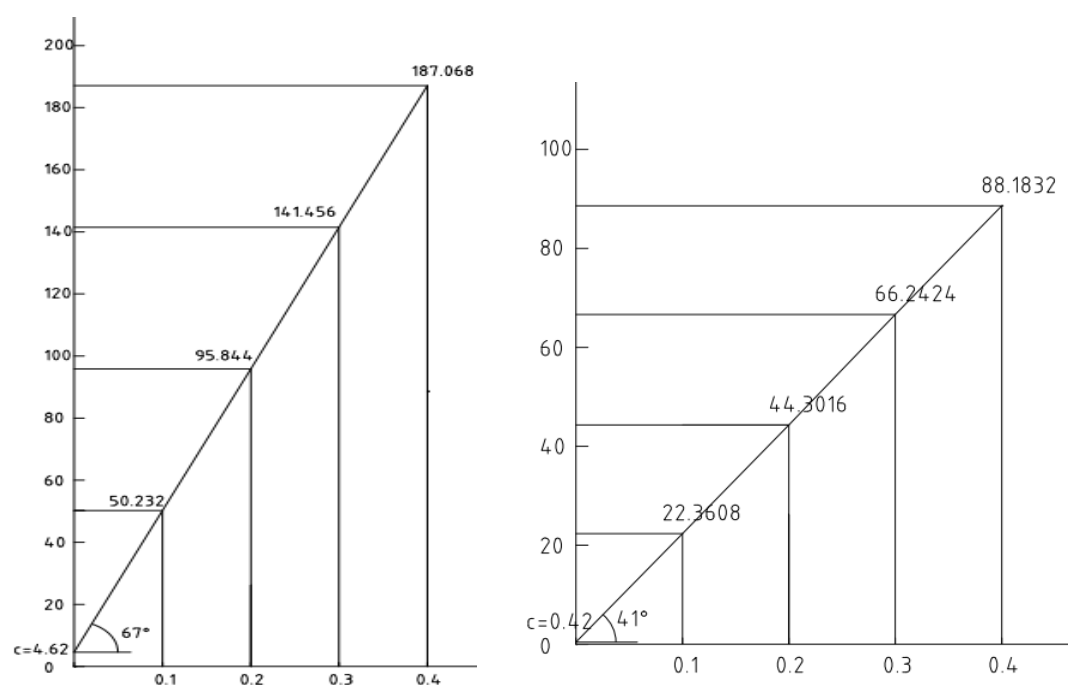

Fig 3.1 Regression equation of solidified soil and undisturbed soil

It can be seen from the regression equation image:Cohesive force of solidified soil is 4.62 and the 
cohesive force of undisturbed soil is 0.42 and it has a lot of improvement. Cured soil friction angle is $67^{\circ}$ and the original soil friction angle is $41^{\circ}$, so it increased by $56 \%$.

\section{Experiment on the Performance Comparison of Cured Soil}

\section{Compression resilience modulus test}

Compression resilience modulus is an important parameter reflecting the strength of pavement structure and an important part of highway design ${ }^{[5,6,7,8]}$. The test was carried out according to the loading plate method of indoor resilient modulus test ${ }^{[2,3]}$. The sample was added in a dose of $5 \%$ of the biological enzyme, and take the experimental age of $28 \mathrm{~d}$, the test sample on the relative humidity of not less than $95 \%$. Under the condition of $20 \square \pm 2 \square$, standard curing $7 \mathrm{~d}, 14 \mathrm{~d}, 21 \mathrm{~d}$ and $28 \mathrm{~d}$ and The compressive modulus of resilience was tested after saturation. The test results are as follows:

Table 4.1 Modulus of resilience of $5 \%$ cured soil

\begin{tabular}{|c|c|c|c|c|c|c|c|}
\hline \multicolumn{8}{|c|}{ Modulus of resilience of $5 \%$ cured soil ( $\mathrm{MPa}$ ) } \\
\hline & \multicolumn{5}{|c|}{ Test value } & \multirow{2}{*}{$\begin{array}{c}\text { Ver value } \\
180\end{array}$} & \multirow{2}{*}{$\begin{array}{c}\begin{array}{l}\text { Repe } \\
\text { value }\end{array} \\
180\end{array}$} \\
\hline $7 \mathrm{~d}$ & 162 & 187 & 190 & 180 & 182 & & \\
\hline $14 d$ & 200 & 210 & 208 & 2321 & 215 & 213 & 215 \\
\hline $21 d$ & 272 & 283 & 251 & 243 & 260 & 262 & 260 \\
\hline $28 \mathrm{~d}$ & 312 & 333 & 308 & 311 & 321 & 317 & 321 \\
\hline
\end{tabular}

Through the above table we can see that the compressive modulus of the bio-enzyme-curable soil at the age of 7 days is $180 \mathrm{MPa}$. With the increase of age, the compressive modulus is increasing gradually ; The compressive modulus of resilience increased by $19.4 \%$ and $44.4 \%$ respectively at $14 \mathrm{~d}$ and $21 \mathrm{~d}$, and the compressive modulus of resilience increased by $78.3 \%$ at $28 \mathrm{~d}$, and reached $321 \mathrm{MPa}$. According to the standard, the compressive modulus of resilience of the solidified soil has met the requirements ${ }^{[4]}$, and the modulus of resilience will continue to increase with age, until the final stability.

\section{Splitting test}

In the front we tested its compressive strength, and then I will test its tensile capacity. The splitting test, also known as the bend test and it happens to meet our needs. The tensile strength index of subgrade is also required, and it is related to the stability and safety of Subgrade ${ }^{[5,6,7,8]}$. Specimen specifications for the $50.46 \mathrm{~mm} * 50 \mathrm{~mm}$ cylinder, the choice of better curing effect of $5 \%$ dose. The sample was filled 24 hours before the experiment, In order to avoid accidental error, 5 times per test and operate as required ${ }^{[3]}$. The preparation and maintenance of specimens are approximately the same as those of compressive modulus of resilience. Placed on the press for splitting test, and strictly control the pressure of the press at $1 \mathrm{~mm} / \mathrm{min}$, respectively, the record of each stage, the sample pressure crushing pressure peak data. Splitting test calculation:

Formula: $\quad R_{i}=\frac{2 P}{\pi d h}$.

In the above formula, $R_{i}$ represents the splitting strength, $P$ represents the destroy the pressure peak, $d$ represents the sample diameter, $h$ represents the sample height after saturating.

The calculated data are as follows: 
Table 4.2 Splitting strength of $5 \%$ solidified soil

\begin{tabular}{|c|c|c|c|c|c|c|c|}
\hline & \multicolumn{5}{|c|}{ Test value } & \multirow{2}{*}{$\begin{array}{c}\begin{array}{c}\text { Ver } \\
\text { value }\end{array} \\
0.232 \\
\end{array}$} & \multirow{2}{*}{$\begin{array}{c}\begin{array}{c}\text { Repe } \\
\text { value }\end{array} \\
0.25 \\
\end{array}$} \\
\hline $7 d$ & 0.20 & 0.21 & 0.29 & 0.25 & 0.21 & & \\
\hline $14 \mathrm{~d}$ & 0.25 & 0.32 & 0.43 & 0.34 & 0.33 & 0.334 & 0.33 \\
\hline $21 d$ & 0.42 & 0.52 & 0.53 & 0.47 & 0.44 & 0.476 & 0.47 \\
\hline $28 \mathrm{~d}$ & 0.58 & 0.59 & 0.59 & 0.62 & 0.76 & 0.628 & 0.62 \\
\hline Remark & \multicolumn{7}{|c|}{ Using $90 \%$ guarantee rate } \\
\hline
\end{tabular}

Through the above table, it is concluded that when the curing time is $7 \mathrm{~d}$, the cleavage strength of enzyme stabilized soil is $0.25 \mathrm{MPa}$, and that of $14 \mathrm{~d}$ increases by $32 \%$ and $88 \%$ compared with that of $21 \mathrm{~d}$, and reaches $0.33 \mathrm{MPa}$ and $0.47 \mathrm{MPa}, 28 \mathrm{~d}$ reached the maximum test $0.62 \mathrm{MPa}$. In a comprehensive analysis, the splitting strength test increases with age, until the peak value is reached.

\section{Conclusions}

(1) Biological enzymes belong to biological soil curing agents, pollution-free environment, without subsequent processing, can be used directly in new materials.

(2) The early strength of solidified soil is high, and the latter strength increases fast. It can shorten the construction period and speed up the construction progress.

(3) Through the splitting test, the solidified soil has higher indirect tensile strength, which can improve the safety and stability of the roadbed, reduce the crack at the base and improve the waterproof performance.

(4) The test of curing period and other constraints, only relevant data measured pre 28d, certainly this is of great significance to the prevention and control of Shenyang area of seasonal frozen roads often occurs in freezing and thawing subsidence, frost and other diseases.

\section{References}

[1] Ministry of Communications of the People's Republic of China. JTJ057-94 Test Code for Stable Material of Inorganic Structural Materials for Highway Engineering[S]. Beijing: China Communications Press, 1996.

[2] Dai Wen-ting, Chen Yao, Chen Xing. Test study on road performance of soils stabilized by BS-100 Model stabilizer in seasonally frozen region. Rock and Soil Mechanics, 2008,29(8).

[3] Zhang Kai. JTJ34 - 2000 Technical specification for highway pavement construction[S]. Beijing: China Communications Press, 2000.

[4] Liu Shun-ni, Lin Zong-tao, Chen Yun-bo. Study on High Water Content Clay Curing Agent[J]. Journal of Geotechnical Engineering, 1998,20 ( 4 ) : 83 - 86.

[5] Li Guo-dong. Experimental Study on Soil Pavement Performance. Northeast Forestry University, 2009.

[6] Yang Hong-yu. Application of Soil Curing Agent in Base Course of Highway Base. Changan University, 2013.

[7] Zhang Xi-kun. Discussion on Application of Liquid - plastic Limit in Subgrade Construction. Journal of Guangdong Vocational and Technical College of Communications, 2002, 3. 
[8] Yu Guang-he. Application Analysis of Biological Enzyme Soil Curing Agent. Transportation Science \& Technology and Economy, 2013, 3. 